\title{
MRI of the Prostate in Germany: Online Survey among Radiologists
}

\section{MRT der Prostata in Deutschland: Online-Umfrage unter Radiologen}

Authors

Affiliations
U. G. Mueller-Lisse ${ }^{1}$, B. Lewerich², U. L Mueller-Lisse ${ }^{3}$, M. Reiser ${ }^{1}$, M. K. Scherr ${ }^{4}$

Department of Radiology, University of Munich, Munich, Germany

Geschäftsstelle, Deutsche Röntgengesellschaft, Berlin, Germany

3 Department of Urology, Interdisziplinäres Onkologisches Zentrum München (IOZ), Munich, Germany

${ }^{4}$ Department of Radiology, Berufsgenossenschaftliche Unfallklinik, Murnau, Germany

\author{
Key words \\ - prostate \\ - MR imaging \\ - MR functional imaging \\ - QA/QC \\ - socioeconomic issues
}

received $\quad 1.10 .2014$

accepted $\quad 3.4 .2015$

\section{Bibliography}

Dol http://dx.doi.org/

10.1055/s-0034-1399566

Published online: 11.6.2015

Fortschr Röntgenstr 2015; 187:

703-711 @ Georg Thieme

Verlag KG Stuttgart . New York .

ISSN 1438-9029

\section{Correspondence \\ Herr Prof. Ullrich Gerd \\ Mueller-Lisse}

Department of Radiology,

University of Munich

Ziemssenstrasse 1

80336 Muenchen

Germany

Tel.: ++ 49/89/51609101

Fax: ++ 49/89/51609102

ullrich.mueller-lisse@med.uni-

muenchen.de

\section{Zusammenfassung \\ $\nabla$}

Ziel: Feststellung struktureller, technischer und kommunikativer Bedingungen bei gezielten MRUntersuchungen der Prostata (MRP) in Deutschland.

Material und Methoden: Mitgliedern der Deutschen Röntgengesellschaft (DRG) wurde per E-Mail ein Link zu einer Online-Umfrage mit acht Fragen zugesandt. Radiologische Institute wurden nach ihrer Struktur, d. h. entweder Klinikabteilung (HD) oder Praxis-Niederlassung (PP), Anzahl radiologischer Fachärzte, Postleitzahlregion, Anzahl der MRPs in 2011, MR-Technologie und MR-Sequenzauswahl, Kommunikationsweise für MRP-Befunde und Rückkopplung von überweisenden Ärzten gefragt. Mehrfach-Antworten des gleichen Instituts wurden zusammengeführt und anonymisiert. Unterschiede in der Anzahl positiver Antworten zu jedem Item waren statistisch signifikant bei $p<0,05$ bei zweiseitigem Testen in Vierfeldertafeln.

Ergebnisse: Die Umfrage erfasste radiologische Fachärzte in 128 Instituten (63 HDs und 65 PPs) in 67/95 deutschen Postleitregionen (71\%). Fast zwei Drittel der Institute führte in 2011 11-50 MRPs durch, wobei häufiger bei 1,5T (116/128, $91 \%$ ) als bei $3,0 \mathrm{~T}(36 / 128,28 \%)$ und überwiegend $\mathrm{mit}$ Oberflächenspulen untersucht wurde $(1,5 \mathrm{~T}, 88 /$ 116, 76\%; 3,0 T, 34/36, 94\%; chi-quadrat, 1,9736, $0,1<\mathrm{p}<0,25)$. Etwa zwei Drittel der 1,5T-Nutzer und $90 \%$ der 3,0T-Nutzer verwendeten wenigstens ein Verfahren der funktionellen MRT (Diffusionsgewichtete Bildgebung, dynamisch-kontrastverstärkte Bildgebung oder MR-Spektroskopie) zur MRP. Befunde mit grafischen Darstellungen der Prostata erstellten 21 von 128 Instituten (16\%). Klinische Rückmeldungen an Radiologen nach MRP erfolgten selten ohne deren besondere Nachfrage (HDs, $32-45 \%$, PPs, $18-32 \%$ ).

Schlussfolgerung: Die MRP war in Deutschland im Jahr 2011 eine weit verfügbare Untersuchung mit geringen Leistungszahlen. Hauptsächlich wurde

\section{Abstract \\ $\nabla$}

Purpose: To assess structural, technical, and communicative aspects of dedicated MR examinations of the prostate (MRP) offered by radiologists in Germany.

Materials and Methods: We conducted an eightitem online survey among members of the German Radiology Society (DRG). Radiological institutions were asked about their structure, i.e., either hospital department (HD) or private practice (PP), number of board-certified radiologists, postal regions, number of MRPs in 2011, MR technology and MR sequences applied, ways to communicate results, and feedback from referring physicians on results of subsequent tests and procedures. Submissions were cleared of redundancies and anonymized. Differences in the number of positive replies to each item were statistically significant at $\mathrm{p}<0.05$ for two-tailed testing in $2 \times 2$ tables.

Results: The survey represented board-certified radiologists in 128 institutions (63 HDs and 65 PPs) in $67 / 95$ German postal regions (71\%). Almost two-thirds of institutions performed 11 to 50 MRPs in 2011, more often at 1.5 T (116/128, $91 \%$ ) than at $3.0 \mathrm{~T}(36 / 128,28 \%)$, and most frequently with surface coils $(1.5 \mathrm{~T}, 88 / 116,76 \%$; $3.0 \mathrm{~T}, 34 / 36,94 \%$; chi-square, $1.9736,0.1<\mathrm{p}<$ 0.25 ). About two-thirds of $1.5 \mathrm{~T}$ users and $90 \%$ of 3.0 Tusers applied at least one functional MR modality (diffusion-weighted imaging, dynamic contrast-enhanced imaging, or MR spectroscopy) for MRP. Reports including graphic representations of the prostate were applied by 21/128 institutions (16\%). Clinical feedback after MRP to radiologists other than upon their own request was infrequent (HDs, $32-45 \%$, PPs, $18-32 \%$ ).

Conclusion: MRP was a widely available, smallvolume examination among radiologists in Germany in 2011. The technology mainstay was a $1.5 \mathrm{~T}$ surface coil examination including at least 
die MRP mit Oberflächenspulen bei 1,5 T unter Einsatz wenigstens eines funktionellen Verfahrens durchgeführt. Gezielte Befundungs-und-Rückmeldungs-Mechanismen zur Qualitätskontrolle waren unterentwickelt.

Kernaussagen:

- Die MRT der Prostata wurde 2011 in mindestens 67 der 95 deutschen Postleitregionen (71\%) angeboten.

- Die MRT der Prostata wurde 2011 in Deutschland weit überwiegend bei 1,5T ohne Endorektalspule durchgeführt.

- In mindestens zwei Dritteln der MRT-Untersuchungen der Prostata in Deutschland wurden 2011 T2WI-Aufnahmen durch wenigstens ein funktionelles Aufnahmeverfahren (meistens DWI, weniger häufig MRS oder DCE) ergänzt.

- Eine strukturierte Befundung unter Nutzung graphischer Elemente erfolgte in weniger als $20 \%$ der teilnehmenden Institute.

- Rückmeldungen von Befunden nachbehandelnder Ärzte an Radiologen nach MRT der Prostata erfolgten weit überwiegend nur auf ausdrückliche Nachfrage der Radiologen. one functional MR modality. Dedicated reporting and feedback mechanisms for quality control were underdeveloped.

Key Points:

- MRI of the prostate was available in at least 67 of 95 German postal regions (71\%) in 2011.

- MRI of the prostate was most often performed at $1.5 \mathrm{~T}$ without an endorectal coil in Germany in 2011.

- At least two thirds of MRI-examinations of the prostate included both T2WI and at least one functional MR test (mostly DWI, less frequently MRS or DCE) in Germany in 2011.

- Structured reporting including graphic elements was offered by less than $20 \%$ of participating radiological institutions.

- Feedback to radiologists from referring physicians on subsequent test results in patients with MRI of the prostate most frequently came only upon special request by the radiologist.

Citation Format:

- Mueller-Lisse UG, Lewerich B, Mueller-Lisse UL etal. MRI of the Prostate in Germany: Online Survey among Radiologists. Fortschr Röntgenstr 2015; 187: 703-711

\section{Introduction}

$\nabla$

Prostate cancer is the most common malignancy of solid organs among men in Germany [1]. Prostate cancer is seen with variable age-adjusted incidence throughout Europe, and a particularly high incidence in North America [2]. Different national and international medical societies have recently developed guidelines for the diagnosis and treatment of prostate cancer, in accordance with evolving concepts of evidence-based medicine and individualized medicine. Recommendations on the use of magnetic resonance imaging (MRI) of the prostate vary, depending on the respective aims and scope of the guidelines, the medical societies issuing the guidelines, the year of publication, the level of evidence in the pertinent medical literature selected to back up any individual recommendation, and the rules of literature selection and evaluation underlying each individual guideline $[3,4]$.

MRI technology for prostate imaging has evolved along the way, and the body of evidence in the pertinent literature is increasing. Evolving technical concepts for MRI of the prostate include the application of 3.0 T MR technology, with or without an endorectal coil (ERC), multi-parametric MRI of the prostate (mpMRI), including both morphological T2-weighted imaging (T2WI) and functional imaging by means of MR spectroscopy (MRS), MR diffusion-weighted imaging (DWI), or dynamic contrast-enhanced MRI (DCE), and, recently, evaluation schemes for the classification of findings at each of the different MR modalities of mpMRI $[3,4]$.

In Germany, a national guideline on the diagnosis and treatment of prostate cancer (S3-Leitlinie) that was based on pertinent literature as selected and formally evaluated according to SIGN (Scottish Intercollegiate Guidelines Network) criteria [5] and PICO (Patient Intervention Comparison Outcome) methods [6] by a federal government agency (Ärztliches Zentrum für Qualität in der Medizin, ÄZQ) [7] and backed up by 14 different German medical societies and patient societies was first issued in 2009 and has since been reviewed and amended twice, in 2011 and in 2013. The German national S3-guideline also comprises recommendations on the application of MR examinations of the prostate that include different technical aspects.

Still, medical guidelines do not necessarily reflect clinical practice within their respective purview. Also, recent medical technology may not be commonly applied in clinical practice although it has been validated in the published literature. To assess structural, technical, and communicative aspects of MR examinations of the prostate offered by radiologists in Germany and compare with both the pertinent German national guideline [4] and emerging evidence on mpMRI $[3,4]$, we conducted an online survey among members of the German Radiology Society (Deutsche Roentgengesellschaft, DRG) regarding the year of 2011, two years after publication of the first version of the pertinent German national guideline [4].

\section{Materials and Methods}

Members of the urogenital radiology working group of the DRG (AG Urogenitale Radiologie, DRG-URO), along with a senior DRG officer, developed an online questionnaire with eight distinct items. Each item included a question, a set of different possible responses, and an additional comment line. The questionnaire was put online by means of a dedicated computer program designed to conduct online surveys (SurveyMonkey ${ }^{\circledR}$, SurveyMonkey Europe Sarl, Luxembourg, https://de.surveymonkey.com). A link to the online survey was added to an e-mail shot that addressed members of the DRG who were board-certified radiologists practicing in Germany, including radiologists who were also board-certified for nuclear medicine studies. The e-mail shot, which was directed at more than 2,000 active individual e-mail accounts of DRG members, was issued twice by the DRG office, once during the second week of December, 2011, and once during the second week of January, 2012. Each time, the link to the online survey was active for one week. All replies were received by the DRG office. The e-mail with the link to the online survey explained the rules of the survey, including that participation was voluntary, and that there was no need for any of the participants to reveal their names or affiliations other than stating the first two digits of their five-digit postal code in one of the items, which would broadly link the response to one of 95 postal regions in Germany. However, participants who submitted their names or affiliations were guaranteed strict confidentiality and anonymized evaluation of their respective responses. Since it was possible that more than one radiologist affiliated with the 
same institution would fill in and submit the online questionnaire, or that the same participant would reply more than once, a senior DRG officer checked all submissions, marked obvious and potential redundancies, and removed any links to specific radiologists or affiliations. Redundancy among two or more submissions was assumed when the replies to all items of the survey were the same and the postal regions matched. The anonymized responses were then forwarded to a DRG-URO researcher who re-checked all submissions and cumulated and abridged apparent redundancies.

The online questionnaire included the following eight different items.

Item 1 asked for the structure of the participating radiological institution, with the possible answers including either hospital department (HD) or private practice (PP), with the latter being subdivided into hospital-based private practice (HPP) and community-based private practice (CPP).

Item 2 asked for the number of board-certified radiologists, including radiologists who were also board-certified for nuclear medicine, affiliated with the submitting radiological institution, with the possible answers including $1,2-3,4-5,6-10$, or more than 10 board-certified radiologists.

Item 3 asked for the first two digits of the five-digit German postal code of the submitting radiological institution, with the possible answers including one of the 95 German postal regions ("Postleitregionen").

Item 4 asked for the number of dedicated magnetic resonance (MR) examinations of the prostate performed at the submitting radiological institution between January 1 and December 31, 2011, with possible answers including none, 1 - 10, 11 - 50, 51 100 , or more than 100 .

Item 5 asked for the respective MR technology applied for dedicated MR examinations of the prostate at the submitting radiological institution between January 1 and December 31, 2011, with the possible answers including MR at $1.5 \mathrm{~T}$ without endorectal coil (ERC), MR at $1.5 \mathrm{~T}$ with ERC, MR at 3.0 T without ERC, and MR at 3.0 T with ERC. The response options included more than one answer and additional comment lines.

Item 6 asked for the respective types of MR sequences applied for dedicated MR examinations of the prostate at the submitting radiological institution between January 1 and December 31, 2011, with the possible answers including T2-weighted imaging (T2WI), MR spectroscopy (MRS), diffusion-weighted MR imaging (DWI), and dynamic contrast-enhanced MR imaging (DCE). The response options included more than one answer and additional comment lines.

Item 7 asked for the way the submitting radiological institution communicated results of dedicated MR examinations of the prostate between January 1 and December 31, 2011, with the possible answers including written radiological report, graphic representation of radiological findings, CD or DVD, laser film printouts, and by means of electronic communication systems, such as computer networks or picture archiving and communication systems (PACS). The response options included more than one answer and additional comment lines.

Item 8 asked for ways in which the submitting radiological institution received feedback from other physicians on results of subsequent tests and procedures in the same patient after dedicated MR examinations of the prostate between January 1 and December 31, 2011, with the possible answers including through physicians' reports or letters forwarded without additional request, through case conferences or review boards or clinical audits, and upon special request by the radiological institution, e.g. by telephone, e-mail, or letter.

\section{Statistical Evaluation}

After checking all submissions and cumulating and abridging apparent redundancies, all individual responses were transferred to Microsoft Excel worksheets (Microsoft Corporation) for further evaluation. The respective numbers and percentages of positive replies of submitting radiological institutions were determined for each individual answer in each of the eight items. Further analysis included the creation of $2 \times 2$ tables that would link up responses to different items. Statistical tests applied to $2 \times 2$ tables included the chi-square test with Yates's continuity correction, or Fisher's exact test when the expected number of elements was five or less in at least one cell of the respective $2 \times 2$ table, with two tails, at a significance level of $\mathrm{p}<0.05$, according to Glantz [8].

\section{Results \\ $\boldsymbol{\nabla}$}

Participating Radiological Institutions (item 1)

During the two different time intervals of the survey, the DRG office received 347 individual responses to the questionnaire. After iterative removal of redundant replies, the remaining responses represented 131 different radiological institutions in Germany which provided the basis of subsequent analyses. Among those 131 radiological institutions, 64 (48.8\%) were HDs, while 67 (51.2\%) were PPs, including $20 \mathrm{HPPs}$ (15.3\%) and 47 CPPs (35.9\%).

\section{Number of Board-Certified Radiologists (item 2)}

Among all radiological institutions in the survey, the relative majority (38/131, 29.0\%) employed between 6 and 10 board-certified radiologists. 2 institutions (1.5\%) each had 1 board-certified radiologist, 26 (19.8\%) had $2-3$ board-certified radiologists, 34 (26.0\%) had 4-5 board-certified radiologists, and $31(23.7 \%)$ had more than 10 board-certified radiologists. Thus, about onehalf of the radiological institutions employed more than 5 board-certified radiologists. However, among the 128 radiological institutions that performed MR examinations of the prostate in 2011 (97.7\% of the responding 131 institutions), HDs significantly more frequently employed more than five board-certified radiologists $(42 / 63,67 \%)$ than PPs $(27 / 65,42 \%$, chi-square, $7.1501,0.005<\mathrm{p}<0.01)$.

\section{Participating German Postal Regions (item 3)}

Among the 95 different German postal regions, 67 (71\%) had at least one radiological institution that performed MR examinations of the prostate in 2011 and participated in this survey ( Fig. 1). 28 postal regions (29\%) had no, 28 (29\%) had 1, 26 $(27 \%)$ had 2,7 ( $7 \%$ ) had 3, $3(3 \%)$ had 4 , and 3 (3\%) had 5 radiological institutions with MR examinations of the prostate in 2011 that participated in this survey.

\section{Number of Dedicated MR Examinations of the Prostate Performed In 2011 (item 4)}

Respective numbers of MR examinations of the prostate performed in 2011 varied greatly among the 128 radiological institutions (63 HDs and 65 PPs). 30 institutions (23\%) counted 1 $10,80(63 \%)$ had $11-50,8(6 \%)$ had $51-100$, and $10(8 \%)$ performed more than 100 prostate MR examinations in 2011. There 


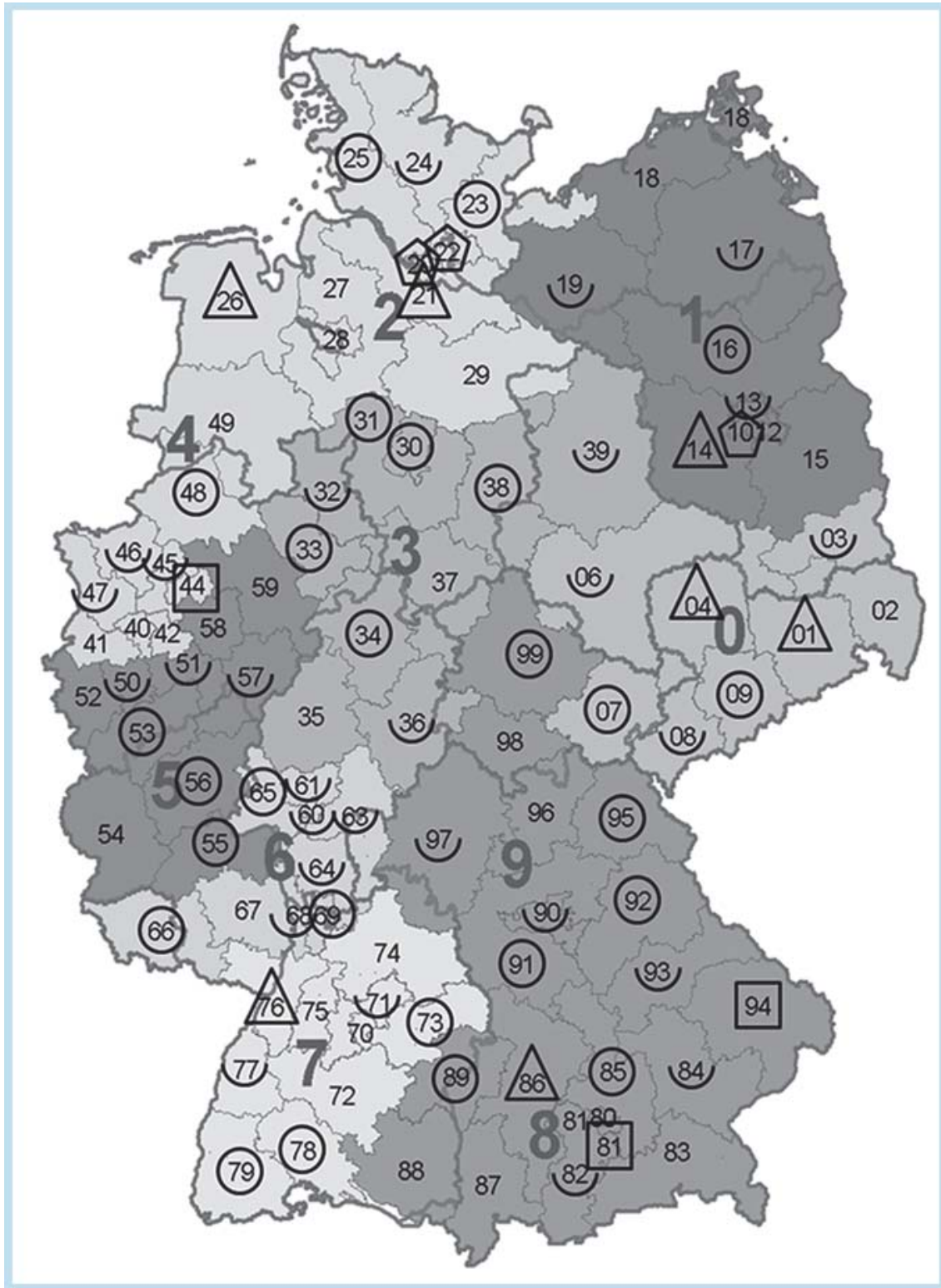

Fig. 1 Distribution over 95 different German postal regions of 128 radiological institutions in the survey that performed MRI of the prostate in 2011: there were 0 (no mark), 1 (semi-circle), 2 (full circle), 3 (triangle), 4 (square), or 5 (pentagon) institutions in each postal region. [map modified from: 30]

Abb. 1 Verteilung der 128 teilnehmenden Institute mit MRT der Prostata in 2011 über die 95 deutschen Postleitregionen: In den verschiedenen Postleitregionen gab es jeweils 0 (keine Markierung), 1 (Halbkreis), 2 (Kreis), 3 (Dreieck), 4 (Viereck) oder 5 (Fünfeck) Institute mit MRT der Prostata [Karte modifiziert nach: 30 ].

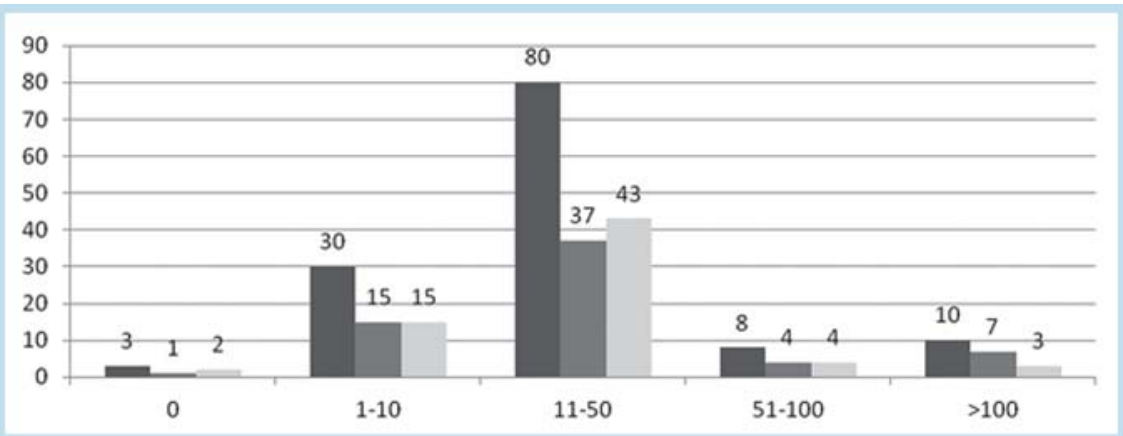

Fig. 2 Distribution of the number of MR examinations of the prostate performed in 2011 (x-axis) among the 131 radiological institutions (dark gray bars) in the survey (y-axis): among 128 radiological institutions with MRI of the prostate, there were 63 hospital departments (medium gray bars) and 65 private practices (light gray bars).
Abb. 2 Verteilung der Anzahlen an MRT-Untersuchungen der Prostata in 2011 (X-Achse) unter den 131 an der Umfrage teilnehmenden radiologischen Instituten (dunkelgraue Balken, Y-Achse): Von 128 Instituten mit MRT der Prostata waren 63 Krankenhausabteilungen (mittelgraue Balken) und 65 Praxisniederlassungen (hellgraue Balken). were no significant differences between the respective proportions of HDs $(11 / 64,17 \%)$ and PPs $(7 / 67,10 \%)$ with more than
50 prostate MR examinations in 2011 (chi-square, 0.7503, $0.25<p<0.50$, $\odot$ Fig. 2). Also, there was no significant association 


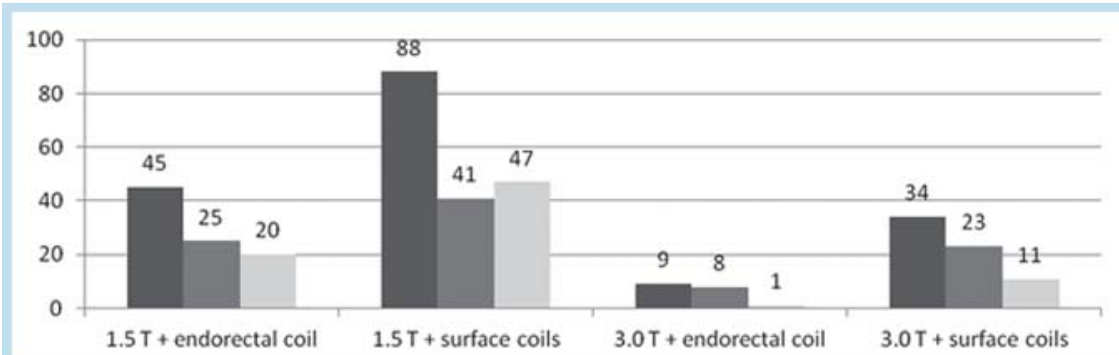

Fig. 3 Distribution of MR technology applied (x-axis) among 128 radiological institutions (dark gray bars) in the survey that performed MRI examinations of the prostate in 2011 (y-axis): there were 63 hospital departments (medium gray bars) and 65 private practices (light gray bars).

Abb. 3 Verteilung der verwendeten MR-Technologie (X-Achse) unter den 128 an der Umfrage teilnehmenden radiologischen Instituten mit MRT der Prostata in 2011 (dunkelgraue Balken, Y-Achse): Darunter waren 63 Krankenhausabteilungen (mittelgraue Balken) und 65 Praxisniederlassungen (hellgraue Balken).

between the number of board-certified radiologists and the number of MR examinations of the prostate performed in 2011. 5 of 59 radiological institutions with up to 5 board-certified radiologists (8\%), and 13/69 (19\%) employing more than 5 board-certified radiologists had more than 50 prostate MR examinations in 2011 (chi-square, 2.0352, $0.10<\mathrm{p}<0.25$ ).

\section{MR Technology Applied to Dedicated Prostate Examinations (item 5)}

Among the 128 radiological institutions that performed MR examinations of the prostate in 2011, 116 (90.6\%) applied $1.5 \mathrm{~T}$ technology, including 55 HDs and 61 PPs, and 36 (28.1\%) used 3.0 T scanners, including 25 HDs and 11 PPs. In addition, free comments revealed that 3 institutions (2.3\%) applied 1.0 T MR technology, and another 3 offered MRI-guided biopsy of the prostate. The majority of 1.5 T users did not apply ERCs for MR examinations of the prostate. Among the 116 users of $1.5 \mathrm{~T}$ technology, 88 (76\%) applied surface coils, including 41 HDs and 47 PPs, while 45 (39\%) applied ERCs, including 25 HDs and 20 PPs (chisquare, $0.6322,0.25<\mathrm{p}<0.50$, no significant difference between HDs and PPs; $\odot$ Fig. 3). Among radiological institutions applying 1.5 T technology, those performing more than 50 prostate MR examinations in 2011 offered ERC examinations significantly more often $(18 / 24,75 \%)$ than those performing 50 or fewer examinations $(24 / 105,23 \%$, including multiple answers by the same institution; chi-square, 21.8722, p<0.001). In turn, 34 of 36 radiological institutions (94\%) examined prostates at $3.0 \mathrm{~T}$ with surface coils, including 23 HDs and 11 PPs, while 9 (25\%) applied ERCs, including 8 HDs and 1 PP (Fisher's exact test, $\mathrm{p}=0.1679$, not significant, including multiple answers by the same institution). The respective rates of ERC application did not differ significantly between users of $1.5 \mathrm{~T}$ and 3.0 T technology (chi-square, 1.9736, $0.1<\mathrm{p}<0.25$; $~$ Fig. 3). Among radiological institutions applying 3.0 T technology, those performing more than 50 prostate MR examinations in 2011 offered ERC examinations significantly more often $(6 / 14,43 \%)$ than those performing 50 or fewer examinations $(3 / 29,10 \%$, including multiple answers by the same institution; Fisher's exact test, $\mathrm{p}=0.0195$ ).

\section{Morphologic and Functional MR Sequences for Dedicated Examinations of the Prostate (item 6)}

All of the 116 radiological institutions that examined prostates at 1.5 T in 2011 applied T2WI MR sequences. Functional MR sequences were added by 91/116 institutions (78\%). 21 of 116 radiological institutions (18\%) offered MRS, DWI and DCE; 39
(34\%) offered two different functional MR sequences, including 4 (3\%) with MRS and DWI, 2 (2\%) with MRS and DCE, and 33 (28\%) with DCE and DWI, while 31 (27\%) offered only one functional MR sequence, including 1 (1\%) with MRS, 18 (16\%) with DWI, and 12 (10\%) with DCE.

MRS was performed at $1.5 \mathrm{~T}$ by 28 institutions (24\%), including significantly more HDs (19/55, 35\%) than PPs (9/61, $15 \%$; chi-square, 5.1531, $\mathrm{p}<0.025$ ), and significantly more institutions with more than 50 prostate examinations $(12 / 18,67 \%)$ than with 50 or less $(16 / 98,16 \%)$ in 2011 (chi-square, 18.3855, p<0.001).

DWI at 1.5 T was available in 76 institutions (66\%), including 41 of 55 HDs (75\%), and 35 of 61 PPs (57\%; chi-square, 3.0517, $0.05<\mathrm{p}<0.10$, not significant), as well as 61 of 98 institutions with up to 50 prostate examinations (62\%), and 15 of 18 with more than 50 prostate examinations (83\%) in 2011 (chi-square, $2.1328,0.10<\mathrm{p}<0.25$, not significant).

DCE at $1.5 \mathrm{~T}$ was used in 68 institutions (59\%), including 36 of 55 HDs $(65 \%)$ and 32 of 61 PPs (52\%; chi-square, 1.5136, $0.1<\mathrm{p}<0.25$, not significant), as well as 56 of 98 institutions (57\%) with up to 50 , and 12 of $18(67 \%)$ with more than 50 prostate examinations in 2011 (chi-square, 0.2438, p >0.50, not significant; $\odot$ Fig. 4).

All of the 36 radiological institutions that examined prostates at 3.0 T in 2011 applied T2WI MR sequences. Functional MR sequences were added by 35/36 institutions (97\%). 18 of 36 radiological institutions (50\%) offered MRS, DWI and DCE; 11 (31\%) offered two different functional MR sequences, including 1 (3\%) with MRS and DWI, and 10 (28\%) with DCE and DWI, while 6 (17\%) offered only one functional MR sequence, including 3 (8\%) with DWI, and 3 (8\%) with DCE. MR examinations of the prostate that included two or more functional sequences thus were significantly more frequent at $3.0 \mathrm{~T}$ than at $1.5 \mathrm{~T}$ (29/36 vs. $60 / 116$, chi-square, 8.2598, $0.001<\mathrm{p}<0.005$ ).

MRS was performed at $3.0 \mathrm{~T}$ by 19 institutions (53\%), including 16 of 25 HDs (64\%) and 3 of 11 PPs (27\%; Fisher's exact test, $\mathrm{p}=0.0392$ ). DWI at 3.0 T was available in 32 institutions ( $89 \%)$, including 23 of 25 HDs (92\%) and 9 of 11 PPs (82\%; Fisher's exact test, $\mathrm{p}=0.2801$, not significant). DCE at 3.0 T was used in 31 institutions (86\%), including 24 of 25 HDs (96\%) and 7 of 11 PPs (64\%; Fisher's exact test, $\mathrm{p}=0.0219 ; 0$ Fig. 4 ).

In all, functional MR examinations were significantly more frequently applied at 3.0 T than at $1.5 \mathrm{~T}$ in 2011 in this survey (35/ 36 vs. $91 / 116$, chi-square, $5.5694,0.01<\mathrm{p}<0.025)$. The differences were slightly greater for MRS (19/36, 53\% at 3.0T, vs. 28/ $116,24 \%$ at $1.5 \mathrm{~T}$; chi-square, $9.2519, \mathrm{p}<0.005)$ than for DCE $(31 /$ 


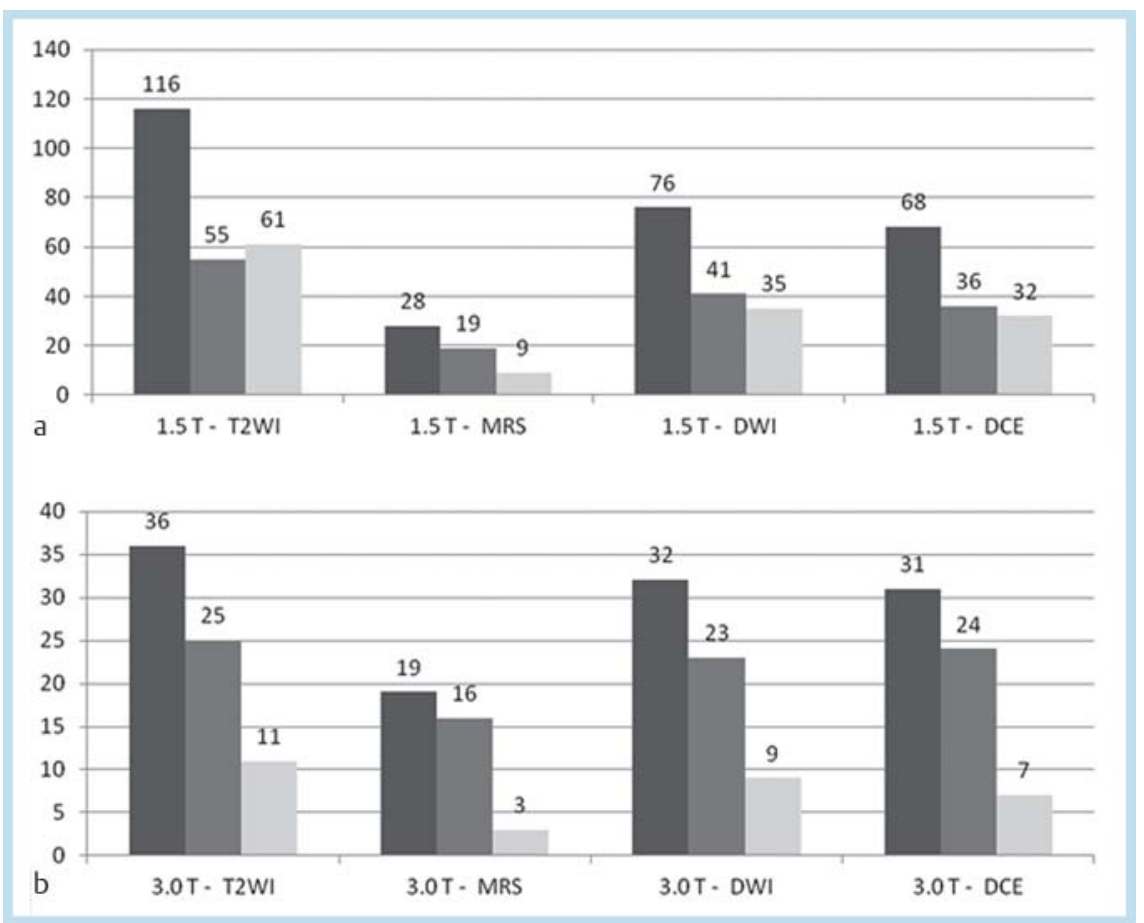

Fig. 4 Application of morphological and functional MR sequences for examinations of the prostate ( $x$-axis) among 128 radiological institutions (dark gray bars) in the survey that performed MRI examinations of the prostate in 2011 (y-axis): there were 63 hospital departments (medium gray bars) and 65 private practices (light gray bars). T2WI - T2-weighted MR imaging, MRS - MR spectroscopy, DWI - diffusion-weighted MR imaging, DCE - dynamic, contrast-enhanced MR imaging. a The upper panel shows MR sequences applied at $1.5 \mathrm{~T}$ (116 different radiological institutions). b The lower panel shows MR sequences applied at 3.0 T (36 different radiological institutions).
Abb.4 Einsatz morphologischer und funktioneller MR-Sequenzen für die Untersuchung der Prostata (X-Achse) unter den 128 an der Umfrage teilnehmenden radiologischen Instituten mit MRT der Prostata in 2011 (dunkelgraue Balken, Y-Achse): Darunter waren 63 Krankenhausabteilungen (mittelgraue Balken) und 65 Praxisniederlassungen (hellgraue Balken). T2WI - T2-gewichtete MR-Bildgebung, MRS - MR-Spektroskopie, DWI diffusionsgewichtete MR-Bildgebung, DCE - dynamisch, kontrastverstärkte MR-Bildgebung. a die obere Grafik zeigt die Verwendung der verschiedenen MR-Sequenzen bei 1,5T (116 verschiedene radiologische Institute). b die untere Grafik zeigt die Verwendung der verschiedenen MR-Sequenzen bei 3,0T (36 verschiedene radiologische Institute).
36, $86 \%$, vs. 68/116, 57\%; chi-square, 7.9719, p<0.005), and smallest for DWI $(32 / 36,89 \%$, vs. 76/116, 66\%; chi-square, 6.2043, $0.010<\mathrm{p}<0.025$; item 6).

Free comments revealed that among the 128 radiological institutions in the survey that performed MR examinations of the prostate in 2011, 3 (2\%) HDs with at least 4 board-certified radiologists and more than 10 diagnostic MR examinations of the prostate in 2011 offered MRI-guided prostate biopsies.

\section{Communication of Radiological Findings from MR Examinations of the Prostate (item 7)}

Written radiological reports were the most frequently applied way to communicate results of MR examinations of the prostate, with 126 of 128 radiological institutions (98.4\%, including 61 HDs and 65 PPs) using this method in 2011. Graphic representations of MR findings were generated by 21 institutions (16\%, including 13/63 HDs, $21 \%$, and 8/65 PPs, $12 \%$; chi-square, $1.0674,0.25<\mathrm{p}<0.50$, not significant). MR images were communicated by means of $C D$ or DVD in 98 institutions (77\%, including 40/63 HDs, 63\%, and 58/ 65 PPs, 89\%; chi-square, 10.4203, $0.001<\mathrm{p}<0.005)$, while 12 institutions (9\%) printed images on laser films, including 2/63 HDs (3\%) and 10/65 PPs (15\%; chi-square, 4.2686, $0.025<\mathrm{p}<0.050$ ). Electronic data transfer, without reference to specific means, was applied by 57 institutions (45\%), including 41/63 HDs (65\%) and 16/65 PPs (25\%; chi-square, 19.5999, p < 0.001).

\section{Feedback to Radiologists Performing MR Examinations} of the Prostate (item 8)

Ways of providing feedback to the radiological institutions regarding the results of subsequent tests and procedures in the same patient by other physicians after dedicated MR examinations of the prostate differed between HDs and PPs. No feedback at all came to 42 of 128 radiological institutions (32.8\%), including 6 of 63 HDs (10\%) and 36 of 65 PPs (55\%; chi-square, 28.4762, $\mathrm{p}<0.001)$. Written reports on subsequent tests and procedures were issued to radiological institutions at no additional request in 41 cases (32.0\%), including 20/63 HDs (32\%) and 21/65 PPs (32\%; chi-square, 0.0147, p >0.5, not significant). Feedback was provided to 57 of 128 radiological institutions (45\%), including 45/63 HDs (71\%) and 12/65 PPs (18\%; chi-square, 34.2237, $\mathrm{p}<0.001$ ), by means of case conferences, review boards, or clinical audits. Feedback upon special request by the radiologist came to 80 institutions (63\%), including 43/63 HDs (68\%) and 37/65 PPs (57\%; chi-square, $1.3024,0.25<\mathrm{p}<0.50$, not significant).

\section{Discussion}

$\nabla$

The most important results were that this survey represented 128 different radiological institutions in 67 of the 95 German postal regions, with an equal distribution among HDs and PPs, that almost two-thirds of participants performed between 11 
and 50 MRs of the prostate in 2011, that more than $90 \%$ applied 1.5 T MR scanners for prostate imaging, that more than $75 \%$ used surface coils without ERCs, that about two-thirds of $1.5 \mathrm{~T}$ users and almost $90 \%$ of 3.0 T users applied at least one functional MR modality for prostate imaging, and that clinical feedback to radiologists performing MR examinations other than upon their own request was infrequent outside of HDs.

The online survey was answered by 131 different radiological institutions that employed between 1 and more than 10 board-certified radiologists who practiced in Germany in 2011. According to data issued by the German government agency for statistical issues (Statistisches Bundesamt), there were 4,362 board-certified radiologists practicing for patients with general health insurance coverage in Germany in 2011 [9]. Therefore, results of the online survey are likely to reflect the working situation of only a fraction of the board-certified radiologists practicing in Germany in 2011. Although the proportion of radiologists who performed MR examinations of the prostate may be over-represented in the survey, because participation in the survey may have been more appealing to radiologists who actually perform MRI of the prostate, the true geographical coverage of German postal regions with MR examinations of the prostate in 2011 is likely to be under-represented. While it would appear to be possible that replies from different radiological institutions were erroneously considered to have come from the same institution, the rules of the iterative review process make this source of error unlikely. There were no significant differences between HDs and PPs in the respective prostate MR caseloads in 2011. MR imaging of the prostate was a low-volume issue for the vast majority of HDs and PPs, since almost two-thirds of the participants performed between 11 and 50 MRs of the prostate in 2011, and almost one-quarter performed 10 or less. The respective prostate MR caseloads did not appear to depend on the structure (i. e., HD or $\mathrm{PP}$ ) or on the number of board-certified radiologists of the radiological institutions. Since participants were not asked to reveal their respective expertise in interpreting MR examinations of the prostate, the potential influence of the presence or lack of specific expertise on the case load was not assessed. While no other immediate conclusion can be derived from these data, previous research has demonstrated that dedicated training and increasing experience with MR examinations of the prostate may improve radiologists' accuracy [10]. Refresher courses, seminars, and workshops on MR examinations of the prostate should therefore be used as a forum for quality assurance among radiologists interested in prostate imaging.

More than $90 \%$ of the participants of this survey applied $1.5 \mathrm{~T}$ MR scanners for prostate imaging, either exclusively or alternately to $3.0 \mathrm{~T}$ platforms. In turn, less than $30 \%$ of participants offered MR examinations of the prostate at $3.0 \mathrm{~T}$. Thus, in contrast to trends in current original research on MR examinations of the prostate and patterns of use among members of the Society of Abdominal Radiology and Texas Radiological Society affiliated with academic centers [11], $1.5 \mathrm{~T}$ technology still represented the mainstay of prostate MR imaging in Germany in 2011. However, in contrast to current German guideline recommendations [4], more than $75 \%$ of those participants who performed MR examinations of the prostate at 1.5 T used surface coils, but no ERCs. The guideline recommendation was based on a meta-analysis that was published in 2002 and summarizes radiological research experience gathered prior to 2000 [12]. Due to a lack in the radiological literature of subsequent comparative technology assessment for prostate imaging at $1.5 \mathrm{~T}$, it remains unclear if the conclusions of the meta-analysis [12] still apply to current $1.5 \mathrm{~T}$ technology, or if they are technically outdated. On the other hand, our analysis shows that three-quarters of those participants who performed more than 50 MR examinations of the prostate at $1.5 \mathrm{~T}$ in 2011 , but less than one-quarter of those who did less applied ERCs. Thus, it appears that the application of dedicated technology is caseload-driven. Although the differences were less pronounced, participants performing more than 50 MR examinations of the prostate at 3.0 T in 2011 applied ERCs significantly more often than those who did less. Since pertinent literature remains inconclusive, current German and European guidelines make no statement for or against ERC application in prostate MR examinations at 3.0 T [3, 4].

Morphologic imaging of the prostate relies on T2WI according to current guidelines and meta-analysis [3, 4]. Among participants of this survey who performed MR examinations of the prostate in 2011, all applied T2WI. A recent survey among members of the Society of Abdominal Radiology and Texas Radiological Society affiliated with academic centers came to the same result [11]. All of the functional MR imaging methods, including MRS, DWI, and DCE, were applied at both $1.5 \mathrm{~T}$ and 3.0 T among the participants of this survey, if at different proportions. In all, functional imaging was significantly more frequently applied and significantly more often involved two or more functional MR sequences at 3.0 T than at $1.5 \mathrm{~T}$, and among participants performing more than 50 MR examinations of the prostate in 2011. It appears therefore that the decision for more comprehensive MR examinations of the prostate was driven by both the availability of larger, potentially more modern MR scanners and the presence or expectation of a higher case load. MRS, as the oldest and bestvalidated functional MR method for prostate examinations at the time of the survey, also was the one least frequently used among participants of this survey. However, it was more frequently applied in Germany, at both $1.5 \mathrm{~T}$ and 3.0 T, than in a recent survey among academic centers in the US [11]. MRS was applied more often at 3.0 T than at $1.5 \mathrm{~T}$, and in HDs rather than in PPs. MRS is currently the only functional MR method recommended by German guidelines [4], based on pertinent literature selected and evaluated according to SIGN criteria, representing levels of evidence ranging from $1+$ to 3 as defined by the US Agency of Health Care Policy and Research [5]. However, MRS is considered to be optional, but not mandatory for MR examinations of the prostate according to recent European recommendations [3] which are based on a consensus conference among a group of experts, or evidence level 4, as defined by SIGN [5]. MRS requires additional software and training to perform, evaluate, and interpret, and its results are displayed in spectra rather than images [13], which may be less intuitive for radiologists than DWI or DCE. While MRS adds specificity to the detection and localization of prostate cancer by means of T2WI [14], the combined application of T2WI and MRS also demonstrates a high negative predictive value for the results of subsequent prostate biopsy in patients with elevated PSA levels, clinical suspicion of prostate cancer and negative previous prostate biopsy results [15]. One recent mono-institutional prospective randomized controlled trial demonstrates that combined T2WI, MRS, and DCE with subsequent targeted and systematic randomized biopsies under transrectal ultrasonography (TRUS) guidance significantly improves prostate cancer detection when compared with TRUS-guided, systematic randomized biopsies alone in patients with one previous negative prostate biopsy and PSA serum levels of $4.0-10.0 \mathrm{ng} / \mathrm{ml} \mathrm{[16].}$ DCE-MRI was the second most frequently applied functional MR 
method in prostate imaging both at $1.5 \mathrm{~T}$ and $3.0 \mathrm{~T}$ in this survey, similar to a recent survey among US-American academic centers [11]. Although being equally applied at $1.5 \mathrm{~T}$ between HDs and PPs and between participants performing more or less than 50 prostate MR examinations in 2011, DCE at 3.0 T was more often applied in HDs than in PPs. While being more demanding than T2WI in patient preparation, including consent to contrast media application, intravenous access, and injection of contrast media during the examination, DCE also requires additional software and post-processing time for evaluation and data interpretation. The latitude of available software, whether custom-made or commercially available $[16,17]$ and of model-based or modelfree approaches to data evaluation [18] has led to different recommendations in current guidelines on prostate imaging. While the European Society of Urogenital Radiology (ESUR) guideline advocates DCE [3], the German S3-guideline does not recommend its application to prostate imaging, due to a lack of consistency within the published literature [4]. DWI, in turn, was the most frequently applied functional MR method in prostate examinations performed at both $1.5 \mathrm{~T}$ and $3.0 \mathrm{~T}$, with no significant differences between HDs and PPs, and between participants with higher and lower workloads than 50 cases in 2011, and showed the smallest difference between users of $1.5 \mathrm{~T}$ and 3.0 T technology. Similarly, a recent survey among academic centers in the US showed that $95 \%$ applied DWI in MR examinations of the prostate [11]. Reasons may include that DWI provides images that are immediately available, without additional post-processing, that the scientific concept of demonstrating the decrease in free motion of water molecules within tissue that is due to increased cellular volume and decreased inter-cellular interstitial space has been known for a long time from MRI of the brain, that required software is essentially available on most modern MR scanners, and that DWI takes little additional scan time and no additional patient preparation. On the other hand, a summary and analysis of original research on DWI of the prostate demonstrates that DWI technology and DWI results differed vastly between studies $[19,21]$. As for DCE, the European Society of Urogenital Radiology (ESUR) guideline advocates DWI [3], while the German S3-guideline currently does not recommend its application to prostate imaging, due to a lack of consistency in technology and test quality parameters among a plethora of small-scale studies, including many pilot studies, within the evaluated literature [4]. This view has recently been corroborated by pertinent meta-analyses of DWI in the detection of prostate cancer, although those metaanalyses suggest that aggregate test quality parameters for DWI are high, particularly when DWI is combined with T2WI [20, 21]. With increasing clinical research experience and improved understanding of the physiological and clinical limits of DWI of the prostate [22], it currently appears that DWI of the prostate will be firmly established and generally available in prostate imaging in the near future. Free comments revealed that MR-guided biopsy of the prostate was performed by three HDs participating in the survey in 2011. Although the published literature on this topic has since increased in volume [23], it remains unclear at this juncture if the number of institutions that offer MR-guided prostate biopsy has increased along the way. However, the pertinent German national guideline [4] includes MR-guided prostate biopsy as an option in patients with suspicion of prostate cancer and previously negative prostate biopsy results.

In 2011, communication of findings from MR examinations was almost exclusively based on written radiological reports, while graphic representations of MR findings were generated by a min- ority of institutions, with no significant differences between HDs and PPs. One reason may be that current radiological reporting systems are based on speech recognition with transfer to text files that usually do not accept graphic elements within the reports they generate. However, it has since been suggested that the location of radiological findings from MR of the prostate should be reported according to multi-region schemes [3] which derive from the sextant scheme that underlies both previous research on the detection and localization of prostate cancer by means of MR examinations [14, 24] and various schemes for ultrasound-guided prostate biopsy [25]. The PI-RADS classification, as a reporting tool for multi-parametric MR examinations of the prostate [3, 26], was not in use in Germany in 2011 and has only lately been subjected to clinical research in MR examinations of the prostate in Germany [27-29]. MR images were most often made available to patients and referring physicians by means of CD or DVD, while less than $10 \%$ of participating radiologists still used laser films. While PPs more frequently issued CDs or DVDs, almost two-thirds of HDs applied means of electronic data transfer to pass on MR images of the prostate. Communication of prostate images therefore was mainly electronic in 2011, with selection of the specific means of data transfer most likely being based on the availability of electronic network systems.

Feedback to radiological institutions on results of subsequent tests and procedures represents an important mechanism of quality assurance in clinical medicine. It is unfortunate that many radiological institutions who performed MR examinations of the prostate in Germany in 2011 only obtained such feedback upon their own active request, if at all. HDs who offered MR examinations of the prostate in 2011 were at an advantage, because they more frequently received feedback through case conferences, review boards, or clinical audits than PPs. Although there is currently a lack of formal evidence, it may be assumed that formal feedback to radiologists on the results of clinical tests and procedures performed after MR examinations of the prostate would help to improve care for patients with diseases of the prostate. Current guidelines [3,4] do not include recommendations on clinical feedback schemes that would involve radiologists.

In conclusion, based on the response of radiologists practicing in 128 different radiological institutions in Germany, MR examinations of the prostate in 2011 were a low case load issue for most radiological institutions, with a wide geographical spread, a firm basis in T2WI at $1.5 \mathrm{~T}$ with surface coils, but without an ERC, and strong tendencies toward additional functional imaging modalities, particularly DWI. Institutions with higher caseloads significantly more often applied more sophisticated technology, including ERCs, 3.0T MR scanners, and multi-parametric MR examinations. Means of electronic image documentation and transfer were widely applied, while reporting made little use of graphic elements despite emerging recommendations. Feedback to radiologists regarding results of subsequent clinical tests and procedures was underdeveloped. Response to the online questionnaire demonstrates that adherence to the evidence-based German guideline was low among users of $1.5 \mathrm{~T}$ technology, who represented the vast majority in this survey, while clinical practice in Germany in 2011 was closer to recommendations of the first version of the consensus-based guideline of the European Society of Urogenital Radiology (ESUR). 


\section{References}

1 Robert Koch Institut (RKI), Gesellschaft der epidemiologischen Krebsregister in Deutschland (GEKID). Krebs in Deutschland 2003-2004. Häufigkeiten und Trends. 6th ed. Berlin: RKI; 2008

2 Haas GP, Delongchamps N, Brawley OW et al. The worldwide epidemiology of prostate cancer: perspectives from autopsy studies. Can J Urol 2008; 15: 3866 - 3871

3 Barentsz JO, Richenberg J, Clements R et al. ESUR prostate MR guidelines 2012. Eur Radiol 2012; 22: 746-757

4 Leitlinienprogramm Onkologie (Deutsche Krebsgesellschaft, Deutsche Krebshilfe, AWMF): Konsultationsfassung: Interdisziplinäre Leitlinie der Qualität S3 zur Früherkennung, Diagnose und Therapie der verschiedenen Stadien des Prostatakarzinoms, Langversion 2.2, [2014] AWMF Registernummer: 034/022OL. http://leitlinienprogramm-onkologie.de/Leitlinien.7.0.html (Zugriff am: 14.06.2014)

5 SIGN, Scottish Intercollegiate Guidelines Network, Healthcare Improvement Scotland, Gyle Square, 1 South Gyle Crescent, Edinburgh EH12 9EB, Scotland, UK; Web contact duncan.service@nhs.net. Section 6: Systematic Literature Review; Last accessed website 20140211

6 van Loveren C, Aartman IH. The PICO (Patient-Intervention-Comparison-Outcome) question. Ned Tijdschr Tandheelkd 2007; 114: 172 -178

7 Gramsch E, Hoppe JD, Jonitz G et al. (Hrsg). Ärztliches Zentrum für Qualität in der Medizin (ÄZQ). Kompendium Q-M-A. Qualitätsmanagement in der ambulanten Versorgung. 3rd ed. Köln: Dt. Ärzte-Verl; 2008

8 Glantz SA. Primer of Biostatistics. 4th ed. New York: McGraw-Hill Health Professions Division; 1997

9 Statistisches Bundesamt. http://www.gbe-bund.de/oowa921-install/ servlet/oowa/aw92/WS0100/_XWD_PROC?_XWD_210/1/ XWD_CUBE.DRILL/_XWD_238/D.930/12123 accessed on December 11th, 2013

10 Mullerad M, Hricak H, Wang L et al. Prostate cancer: detection of extracapsular extension by genitourinary and general body radiologists at MR imaging. Radiology 2004; 232: 140-146

11 Leake JL, Hardman R, Ojili V et al. Prostate MRI: access to and current practice of prostate MRI in the United States. J Am Coll Radiol 2014; 11: $156-160$

12 Engelbrecht MR, Jager GJ, Laheij RJ et al. Local staging of prostate cancer using magnetic resonance imaging: a meta-analysis. Eur Radiol 2002; 12: $2294-2302$

13 Mueller-Lisse UG, Scherr M. 1H-MR-Spektroskopie der Prostata: Ein Überblick. Radiologe 2003; 43: 481-488

14 Scheidler J, Hricak H, Vigneron DB et al. Prostate Cancer: localization with three-dimensional proton MR spectroscopic imaging - clinicopathologic study. Radiology 1999; 213: 473-480

15 Prando A, Kurhanewicz J, Borges AP et al. Prostatic biopsy directed with endorectal MR spectroscopic imaging findings in patients with elevated prostate specific antigen levels and prior negative biopsy findings: early experience. Radiology 2005; 236: $903-910$

16 Sciarra A, Panebianco V, Ciccariello $M$ et al. Value of magnetic resonance spectroscopy imaging and dynamic contrast-enhanced imaging for detecting prostate cancer foci in men with prior negative biopsy. Clin Cancer Res 2010; 16: 1875-1883

17 Beyersdorff D, Lüdemann L, Dietz E et al. Dynamische kontrastmittelunterstützte MRT der Prostata: Vergleich von zwei Auswerteverfahren. Rofo 2011; 183: 456 - 461

18 Scherr MK, Seitz M, Müller-Lisse UG et al. MR-perfusion (MRP) and diffusion-weighted imaging (DWI) in prostate cancer: quantitative and model-based gadobenate dimeglumine MRP parameters in detection of prostate cancer. Eur J Radiol 2010; 76: 359-366

19 Mueller-Lisse UG, Mueller-Lisse UL, Zamecnik P et al. Diffusionsgewichtete MRT der Prostata. Radiologe 2011; 51: 205 - 214

20 Jin G, Su DK, Luo NB et al. Meta-analysis of diffusion-weighted magnetic resonance imaging in detecting prostate cancer. J Comput Assist Tomogr 2013; 37: 195-202

21 Tan $\mathrm{CH}$, Wei W, Johnson $V$ et al. Diffusion-weighted MRI in the detection of prostate cancer: meta-analysis. Am J Roentgenol Am J Roentgenol 2012; 199: 822 - 829

22 Langer DL, van der Kwast TH, Evans AJ et al. Intermixed Normal Tissue within Prostate Cancer: Effect on MR Imaging Measurements of Apparent Diffusion Coefficient and T2-Sparse versus Dense Cancers. Radiology 2008; 249: 900-908

23 Polanec SH, Helbich TH, Margreiter M et al. Magnetic resonance imaging-guided prostate biopsy: institutional analysis and systematic review. Rofo 2014; 186: $501-507$

24 Mueller-Lisse U, Mueller-Lisse U, Scheidler J et al. Reproducibility of image interpretation in MRI of the prostate: application of the sextant framework by two different radiologists. Eur Radiol 2005; 15: 1826 1833

25 Scattoni V, Maccagnano C, Capitanio $U$ et al. Random biopsy: when, how many and where to take the cores? World J Urol 2014, [Epub ahead of print]

26 Röthke M, Blondin D, Schlemmer HP et al. PI-RADS-Klassifikation: Strukturiertes Befundungsschema für die MRT der Prostata. Rofo 2013; 185: 253-261

27 Baur AD, Maxeiner A, Franiel T et al. Evaluation of the prostate imaging reporting and data system for the detection of prostate cancer by the results of targeted biopsy of the prostate. Invest Radiol 2014; 49: $411-420$

28 Kuru TH, Roethke MC, Rieker P et al. Histology core-specific evaluation of the European Society of Urogenital Radiology (ESUR) standardised scoring system of multiparametric magnetic resonance imaging (mpMRI) of the prostate. BJU Int 2013; 112: 1080-1087

29 Roethke MC, Kuru TH, Schultze S et al. Evaluation of the ESUR PI-RADS scoring system for multiparametric MRI of the prostate with targeted MR/TRUS fusion-guided biopsy at 3.0 Tesla. Eur Radiol 2014; 24: 344 352

30 Kuehn S. Karte der Postleitzahlen mit Zonen der ersten 2 Ziffern der PLZ und den Bundeslandgrenzen. Erstellt am 18. Juni 2003. Copyright Status: $\{\{G F D L\}\}$. Wikimedia Commons: German postcode information.png. Date last modified: 31 October 2013 